\title{
Oligoclonal bands in the cerebrospinal fluid and increased brain atrophy in early stages of relapsing-remitting multiple sclerosis
}

\author{
Bandas oligoclonales en líquido cefalorraquídeo y incremento de la atrofia cerebral en \\ estadios tempranos de pacientes con esclerosis múltiple forma recaída-remisión
}

Juan Ignacio Rojas', Liliana Patrucco', Santiago Tizio², Edgardo Cristiano'

\begin{abstract}
Objective: To determine if the presence of oligoclonal bands (OB) at early stages of multiple sclerosis was associated with higher brain atrophy, when compared with patients without OB. Methods: Relapsing-remitting multiple sclerosis (RRMS) patients with less than two years of disease onset and OB detection in cerebrospinal fluid (CSF) were included. SIENAX was used for total brain volume (TBV), gray matter volume (GMV), and white matter volume (WMV). Results: Forty patients were included, 29 had positive lgG-OB. No differences were found between positive and negative patients in gender, expanded disability status scale (EDSS), treatment received, and T2/T1 lesion load. TBV in positive IgG-OB patients was $1.5 \mathrm{~mm}^{3} \times 10^{6}$ compared with $1.64 \mathrm{~mm}^{3} \times 10^{6}$ in the negative ones $(\mathrm{p}=0.02)$. GMV was $0.51 \mathrm{~mm}^{3} \times 10^{6}$ in positive IgG-OB compared with $0.62 \mathrm{~mm}^{3} \times 10^{6}$ in negative ones ( $\left.p=0.002\right)$. No differences in WMV ( $\left.p=0.09\right)$ were seen. Conclusions: IgG-OB in the CSF was related to neurodegeneration magnetic resonance (MR) markers in early RRMS.
\end{abstract}

Key words: multiple sclerosis, brain atrophy, oligoclonal bands.

\section{RESUMEN}

Objetivo: Evaluar si la presencia de bandas oligoclonales (BO) en líquido cefalorraquídeo (LCR) de pacientes con esclerosis múltiple recaídaremisión (EMRR) se asociaba con mayor atrofia cerebral al inicio de la enfermedad. Métodos: Pacientes con EMRR con menos que dos años del inicio de la enfermedad y en quiénes se realizó la búsqueda de lgG-BO en LCR fueron incluidos. SIENAX fue usado para la medición del volumen cerebral total (VCT), volumen de substancia gris (VSG) y volumen de sustancia blanca (VSB). Resultados: Cuarenta pacientes fueron incluidos, 29 tenían IgG-BO positivo. No fueron encontradas diferencias entre pacientes positivos y negativos en: género, expanded disability status scale (EDSS), tratamiento recibido y carga lesional en resonancia magnética. El VCT en pacientes IgG-BO positivos fue de 1,5 mm ${ }^{3} \mathrm{x}$ $10^{6}$ versus $1,64 \mathrm{~mm}^{3} \times 10^{6}$ en BO negativo $(p=0,02)$. El VSG fue $0,51 \mathrm{~mm}^{3} \times 10^{6}$ BO positivo versus $0,62 \mathrm{~mm}^{3} \times 10^{6} \mathrm{BO}$ negativo ( $p=0,002$ ). No fueron encontradas diferencias en VSB ( $p=0,09)$. Conclusiones: La presencia de IgG-BO en el LCR se asoció con signos de neurodegeneración temprana en este estudio.

Palabras-Clave: esclerosis múltiple, atrofia cerebral, bandas oligoclonales.

Multiple sclerosis (MS) is a chronic, inflammatory, and neurodegenerative disorder of the central nervous system (CNS), which evolves over time clinically by a variable course $^{1}$. The disease is characterized by the appearance of multiple areas of myelin destruction, axonal loss, and reactive gliosis ${ }^{2}$. Advances in the study of the disease pathogenesis have demonstrated not only focal but also diffuse damage affecting white, as well as grey matter and neurodegeneration occurring in early stages ${ }^{2-6}$. This damage and consequent loss of tissue lead into atrophy of the CNS in MS patients, reflecting the underlying and permanent neuroaxonal destruction ${ }^{2,5}$.

Brain atrophy, especially neocortical grey matter atrophy, has a direct link with the disease disability and progression, as previously demonstrated in some cross-sectional and longitudinal studies, being a possible biomarker for worse prognosis when considering physical outcomes in the mid and longterm follow-up $\mathbf{u p}^{3,5,7,8}$. 
Almost 95\% of patients with MS have cerebrospinal fluid (CSF) immunoglobulin in oligoclonal patterns or bands (IgG-OB), with unusual cases of MS OB-negative: 35 to $45 \%$ in the Far East ${ }^{9}$. It is clear nowadays that IgG-OB demonstrate a prognostic role in the conversion to MS in clinical isolated syndrome $(\mathrm{CIS})^{10,11}$. However, in MS patients, their role in prognosis has not been completely understood. Joseph et al., in a retrospective case analysis including 100 IgG-OB negative MS patients, demonstrated that band negative patients have clinical, neuroradiological, and prognostic differences compared with positive ones ${ }^{9}$. These MS patients without IgGOB in CSF were more likely to show atypical presentations at onset and a better prognosis of physical disability during follow-up. Primarily, IgG-OB negative cases were less likely to reach disability endpoints measured by the expanded disability status scale (EDSS), when compared with positive band patients, independently of magnetic resonance (MR), and other clinical features ${ }^{9}$. However, the exact role of IgG-OB in the prognosis of MS patients is not fully understood. In contrast to IgG-OB, it has been demonstrated that lipid-specific IgM oligoclonal bands, when present in MS patients, predict an aggressive course of the disease in terms of new relapses and cumulative disability ${ }^{12,13}$. Despite the fact that IgM lipidspecific has a demonstrated role in prognosis of the disease, it is a more complex and less disseminated technique.

Considering the relevance that brain atrophy, which may be termed as neurodegeneration, might have in predicting the disease evolution at MS onset $\mathrm{t}^{3,5}$ and the role that IgG-OB could have in producing such damage ${ }^{9}$, the aim of this study was to evaluate the relationship between CSF IgG-OB positivity, and the presence of brain atrophy in the MS early onset.

\section{METHODS}

\section{Patients}

This study was designed to be cross-sectional. Patients with remitting-relapsing MS (RRMS) and less than two years of disease onset (defined as the appearance of the first demyelinating symptoms compatible with MS) were included between June 2006 and June 2010 from a cohort of patients from the MS Center of the Hospital Italiano de Buenos Aires, in Argentina. For inclusion, patients had to fulfill $\operatorname{Poser}^{14}$ or McDonald ${ }^{15}$ criteria for dissemination in time and space for MS and were required to have a MR at onset of the disease and without taking steroid treatment for at least 30 days prior to the scan.

\section{Clinical and paraclinical data analyzed}

For patients included in the study, the clinical variables obtained included demographic data, form of clinical onset, and EDSS at the beginning of the disease. Paraclinical data obtained at onset and analyzed were: serological tests for differential diagnosis, including antinuclear antibodies, B12 vitamin and folate levels, syphilis and HIV; IgG-OB detection in CSF was performed by agarose isoelectric focusing combined with immunoblotting and avidin-biotin amplified with double antibody peroxidase staining, as well as in the serum of each patient included. Brain MR was performed on a 1.5 Tesla machine, with a standard head coil (Siemens Avanto) within two months of the first demyelinating event. Spinal MR was also performed if the CIS was a spinal cord syndrome. The MR study included images obtained in the following sequences: T1-weighted conventional spin-echo; T2weighted fast spin-echo; FLAIR spin-echo, and T1-weighted conventional spin-echo after single doses of gadolinium $(0.1 \mathrm{mg} / \mathrm{kg})$. All images had a $5 \mathrm{~mm}$ section thickness and a $0.5 \mathrm{~mm}$ intersection gap.

\section{Brain volume measurements}

Brain volumes were estimated from T1-weighted images with SIENAX, which is a software part of the FSL library (an adaptation of SIENA for cross-sectional measurement) ${ }^{16}$. This software estimates the total brain parenchyma volume (TBV) and then separates it in neocortical grey matter volume (GMV), white matter volume (WMV), and CSF volume. It also estimates the brain volumes from a single image, normalized for skull size. It first strips nonbrain tissue and then uses the brain and skull images to estimate the scaling between the subject's image and standard space. Next, it runs tissue segmentation to estimate the brain tissue volume and multiplies this by the estimated scaling factor to reduce head-size-related variability between subjects ${ }^{16}$.

In addition to brain volume measurements, T1 and T2-weighted lesion volumes at baseline were calculated. SepINRIA software was used to segment and calculate T1 and T2 lesion loads by lesion segmentation edition ${ }^{17}$.

Ethics approval for the cross-sectional study was obtained from the Medical Ethics Committee of Hospital Italiano de Buenos Aires. Written informed consent was then obtained from all participants included in this study.

\section{Statistical analysis}

Data were stored and analyzed in STATA 9.1 software. Differences in variables between patients with and without IgG-OB were examined using Mann-Whitney's U, KruskalWallis, and Fisher's exact tests for continuous and categorical variables, respectively. A $\mathrm{p}<0.05$ was considered statistically significant.

\section{RESULTS}

From a total of 114 evaluated patients, only forty met the inclusion criteria and were subsequently included in the study. Mean age of the sample was $32 \pm 5.6$ years-old and 
mean EDSS was 1.1 \pm 0.5. Demographic, clinical, and paraclinical data of the patients included are displayed in Table 1. Of 40 patients, $29(72.5 \%)$ had positive IgG-OB in the CSF. No differences were found between IgG-OB positive and negative patients in gender, EDSS, time from onset of disease and treatment received, and T2 as well as T1 lesion load (Table 2).

When brain volume was measured, we observed that the TBV in positive IgG-OB patients was $1.5 \mathrm{~mm}^{3} \mathrm{x} 10^{6}$ compared with $1.64 \mathrm{~mm}^{3} \times 10^{6}$ in negative ones $(\mathrm{p}=0.02)$. When neocortical grey matter was evaluated, we found that the GMV was $0.51 \mathrm{~mm}^{3} \times 10^{6}$ in positive IgG-OB versus $0.62 \mathrm{~mm}^{3} \times 10^{6}$ in negative ones $(\mathrm{p}=0.002)$. WMV was $0.98 \mathrm{~mm}^{3} \times 10^{6}$ in positive IgG-OB versus $1.12 \mathrm{~mm}^{3} \times 10^{6}$ in negative ones $(\mathrm{p}=0.09)$, as seen in Table 2 and Figure.

\section{DISCUSSION}

It is currently accepted that brain atrophy is related to neurodegeneration in MS, as well as to physical longterm disability ${ }^{18}$.

Our study has showed that the presence of IgG-OB in CSF at the onset of MS is associated with the presence of brain volume reduction, mainly in neocortical grey matter and independently from the lesion load or other clinical parameters. No differences in lesion load volumes were found; however, an increased tendency of higher lesion load volumes in T2 in positive IgG-OB was observed, with a nearly significant difference.

Our results are in line with a recently published study, in which the presence of lipid-specific IgM-OB in the CSF was related in CIS patients to higher lesion load, higher brain atrophy during the short-term follow-up, and increased probability of conversion to MS compared with patients without this biomarker ${ }^{19}$. A possible explanation could be that the presence of Ig in the CSF, independently of whether it is IgG or IgM, is related to an immunological phenomenon that may be producing brain tissue damage, which would consequently lead to a reduction in measured volumes. Studies are currently demonstrating that the reduction in brain volume (brain atrophy) is related to physical disability in the short and mid-term follow-ups, with this marker being considered as a possible biomarker in the near future that may help to predict the course of the disease in MS patients ${ }^{3,5,18,19}$. On the other hand, the reduction of brain volumes in MS patients could be related to other unexplored and unknown phenomena like reduction of the inflammation (pseudoatrophy) instead of neurodegeneration. However, current evidences move brain atrophy evidences towards neurodegeneration and axonal loss instead of preservation ${ }^{5,19,20}$. Undoubtedly, future studies will elucidate this issue.

Table 1. Demographics at baseline.

\begin{tabular}{lc} 
Variable & $\mathrm{n}=40$ \\
Mean age at onset (years) & $32 \pm 5.6$ \\
Women (\%) & $30(77)$ \\
Mean disease duration (months) & $15 \pm 4.5$ \\
EDSS at onset & $1.1 \pm 0.5$ \\
lgG-OB in CSF (\%) & $29(72.5)$ \\
Mean T2 lesion volume at baseline $\left(\mathrm{mm}^{3}\right)$ & $1,456 \pm 3,650 \mathrm{~mm}^{3}$ \\
Mean T1 lesion volume at baseline $\left(\mathrm{mm}^{3}\right)$ & $368.6 \pm 542 \mathrm{~mm}^{3}$ \\
Disease modifying treatment $(\%)$ & $40(100)$ \\
\hline
\end{tabular}

EDSS: expanded disability status scale; IgG-OB: IgG oligoclonal bands in CSF; CSF: cerebrospinal fluid.

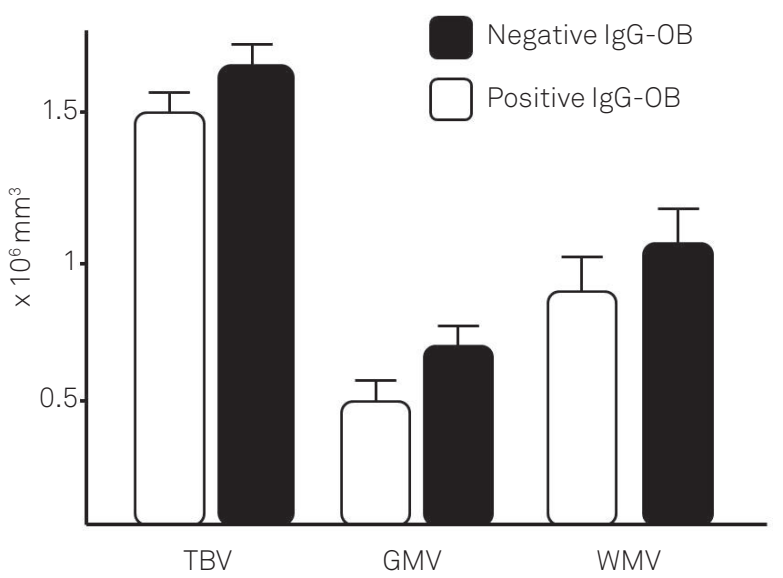

IgG-OB: IgG oligoclonal bands in CSF; TBV: total brain volume; GMV: grey matter volume; WMV: white matter volume; CSF: cerebrospinal fluid.

Figure. Brain volumes measured by the presence or absence of IgG oligoclonal bands in the cerebrospinal fluid.

Table 2. Baseline characteristics comparisons among positive versus negative IgG oligoclonal bands in the cerebrospinal fluid.

\begin{tabular}{lccc} 
Variable & Positive IgG-OB & Negative IgG-OB & p-value \\
\hline Mean age at onset (years) & $30.1 \pm 2.3$ & $33.2 \pm 3.1$ & 0.22 \\
Women (\%) & $17(42.5)$ & $13(32.5)$ & 0.32 \\
Mean disease duration (months) & $13 \pm 3.5$ & $15+2.6$ & 0.25 \\
EDSS at onset & $1.13 \pm 0,6$ & $1.05 \pm 1$ & 0.18 \\
Mean T2 lesion volume at baseline $\left(\mathrm{mm}^{3}\right)$ & $1,956 \pm 2,563$ & $1,478 \pm 2,725$ & 0.08 \\
Mean T1 lesion volume at baseline $\left(\mathrm{mm}^{3}\right)$ & $402 \pm 378$ & $337 \pm 506$ & 0.12 \\
TBV mm ${ }^{3} \times 10^{6}$ & 1.5 & 1.64 & 0.02 \\
GMV mm ${ }^{3} \times 10^{6}$ & 0.51 & 0.62 & 0.002 \\
WMV mm ${ }^{3} \times 10^{6}$ & 0.98 & 1.12 & 0.08 \\
\hline
\end{tabular}

IgG-OB: IgG oligoclonal bands in CSF; TBV: total brain volume; GMV: grey matter volume; WMV: white matter volume; CSF: cerebrospinal fluid. 
Of course, our study has many limitations, and conclusions cannot be drawn from this simple observation. Primarily, this is a cross-sectional study in which a snapshot of the evolution of the disease was taken at the early MS onset in these patients. However, short-term follow-up studies are pointing in this direction as well. Another important limitation that must be addressed is the number of patients included, although it demonstrates significant differences in brain volumes between positive OB patients versus negative ones. Other limitation is that this study has no cognitive correlate in order to test functional impact of brain volume changes. Finally, another limitation is that we did not measure lipid-specific IgM-OB in the CSF, though this is considered to be a more specific biomarker in the course of MS as well as in CIS patients ${ }^{12,13}$. Nevertheless, despite the high proportion of IgG-OB falsenegatives in predicting the course of the disease, we were still able to demonstrate brain volumes changes with the presence of IgG-OB.

In summary, our study found that the presence of IgG-OB in the CSF is related to neurodegeneration of MR markers in patients at an early stage of MS. Further studies that include more patients and follow-up are needed to confirm this initial finding.

\section{References}

1. Noseworthy JH, Lucchinetti C, Rodriguez M, Weinshenker BG. Multiple sclerosis. N Engl J Med 2000;343:938-952.

2. Trapp BD, Peterson J, Ransohoff RM, Rudick R, Mork S, Bo L. Axonal transection in the lesions of multiple sclerosis. N Engl J Med 1998;338:278-285.

3. Fisher E, Rudick RA, Cutter G, et al. Relationship between brain atrophy and disability: an 8-year follow-up study of multiple sclerosis patients. Mult Scler 2000;6:373-377.

4. Sailer M, O'Riordan JI, Thompson AJ, et al. Quantitative MRI in patients with clinically isolated syndromes suggestive of demyelination. Neurology 1999;52:599-606.

5. Di Filippo M, Anderson VM, Altmann DR, et al. Brain atrophy and lesion load measures over 1 year relate to clinical status after 6 years in patients with clinically isolated syndromes. J Neurol Neurosurg Psychiatry 2010;81:204-208.

6. Rocca MA, Agosta F, Sormani MP, et al. A three-year, multiparametric MRI study in patients at presentation with CIS. J Neurol 2008;255:683-691.

7. Fisniku LK, Brex PA, Altmann DR, et al. Disability and T2 MRI lesions: a 20-year follow-up of patients with relapse onset of multiple sclerosis. Brain 2008;131:808-817.

8. Martola J, Bergstrom J, Fredrikson S, et al. A longitudinal observational study of brain atrophy rate reflecting four decades of multiple sclerosis: a comparison of serial 1D, 2D, and volumetric measurements from MRI images. Neuroradiology 2010;52:109-117.

9. Joseph FG, Hirst CL, Pickersgill TP, Ben-Shlomo Y, Robertson NP, Scolding NJ. CSF oligoclonal band status informs prognosis in multiple sclerosis: a case control study of 100 patients. J Neurol Neurosurg Psychiatry 2009;80:292-296.

10. Rojas J, Patruccol L, Cristiano E. Oligoclonal bands and MRI in clinically isolated syndromes: predicting conversion time to multiple sclerosis. J Neurol 2010;257:1188-1191.
11. Tintore M, Rovira A, Rio J, et al. Do oligoclonal bands add information to MRI in first attacks of multiple sclerosis? Neurology 2008;70:1079-1083.

12. Villar LM, Masjuan J, Gonzalez-Porque P, et al. Intrathecal IgM synthesis predicts the onset of new relapses and a worse disease course in MS. Neurology 2002;59:555-559.

13. Villar LM, Masjuan J, Gonzalez-Porque P, et al. Intrathecal IgM synthesis is a prognostic factor in multiple sclerosis. Ann Neurol 2003:53:222-226.

14. Poser CM, Paty DW, Scheinberg L, et al. New diagnostic criteria for multiple sclerosis: guidelines for research protocols. Ann Neurol 1983;13:227-231.

15. Polman $\mathrm{CH}$, Reingold SC, Edan G, et al. Diagnostic criteria for multiple sclerosis: 2005 revisions to the "McDonald Criteria". Ann Neurol 2005;58:840-846

16. Smith SM, Zhang $\mathrm{Y}$, Jenkinson $\mathrm{M}$, et al. Accurate, robust, and automated longitudinal and cross-sectional brain change analysis. Neuroimage 2002;17:479-489.

17. Ebers GC. Environmental factors and multiple sclerosis. Lancet Neurol 2008;7:268-277.

18. Miller DH, Barkhof F, Frank JA, Parker GJ, Thompson AJ Measurement of atrophy in multiple sclerosis: pathological basis, methodological aspects and clinical relevance. Brain 2002;125:1676-1695.

19. Magraner MJ, Bosca I, Simo-Castello M, et al. Brain atrophy and lesion load are related to CSF lipid-specific IgM oligoclonal bands in clinically isolated syndromes. Neuroradiology 2012;54:5-12.

20. Rudick RA, Fisher E, Lee JC, Simon J, Jacobs L. Use of the brain parenchymal fraction to measure whole brain atrophy in relapsingremitting MS. Multiple Sclerosis Collaborative Research Group. Neurology 1999;53:1698-1704 